\title{
Intrahippocampal injection of a lentiviral vector expressing neurogranin enhances cognitive function in 5XFAD mice
}

\author{
Seong Gak Jeon ${ }^{1}$, Moonkyung Kang ${ }^{2}$, Yeon-Soo Kim³ ${ }^{3}$, Dong-Hyun Kim ${ }^{4}$, Dong Woo Nam ${ }^{5}$, Eun Ji Song ${ }^{1}$, \\ Inhee Mook-Jung ${ }^{5}$ and Minho Moon ${ }^{1}$
}

Progressive cognitive declines are the main clinical symptoms of Alzheimer's disease (AD). Cognitive impairment in AD is directly correlated with amyloid beta (Aß)-mediated synaptic deficits. It is known that upregulation of neurogranin $(\mathrm{Ng})$, a postsynaptic protein, contributes to the enhancement of synaptic plasticity and cognitive function. By contrast, downregulation of $\mathrm{Ng}$ expression results in learning and memory impairments. Interestingly, $\mathrm{Ng}$ expression is significantly reduced in the parenchyma of brains with AD. However, the pathological role that downregulated $\mathrm{Ng}$ plays in the cognitive dysfunctions observed in AD remains unclear. Therefore, the present study examined whether enhancing $\mathrm{Ng}$ expression affected cognitive functions in 5XFAD mice, an animal model of AD. We found that the $\mathrm{Ng}$ reductions and cognitive decline observed in 5XFAD mice were restored in mice that were intrahippocampally injected with an $\mathrm{Ng}$-expressing lentiviral vector. Furthermore, overexpression of $\mathrm{Ng}$ upregulated expression of postsynaptic density protein-95 in the hippocampus of 5XFAD mice. These results suggest that the cause of cognitive decline in $\mathrm{AD}$ may be at least partially associated with reduced $\mathrm{Ng}$ levels, and thus, supplementation of $\mathrm{Ng}$ may be an appropriate therapeutic strategy for individuals with AD.

Experimental \& Molecular Medicine (2018) 50, e461; doi:10.1038/emm.2017.302; published online 23 March 2018

\section{INTRODUCTION}

Alzheimer's disease (AD) is one of the most common neurodegenerative disorders, and its main clinical symptoms are progressive cognition impairments. Histopathologically, AD is characterized by the accumulation of neurofibrillary tangles and amyloid plaques in the brain, resulting in the loss of neurons and synapses. ${ }^{1}$ In the early stages of $\mathrm{AD}$, the synaptic protein level is reduced by $\sim 25 \%$, indicating that synaptic loss is an early event in $\mathrm{AD} .^{2}$ Moreover, synaptic failure has been directly linked to cognitive decline and dementia severity in $\mathrm{AD},{ }^{3-5}$ suggesting that the memory loss of patients in the early stages of $\mathrm{AD}$ may be caused by synaptic dysfunction, rather than by neuronal death.

One factor that is known to cause synaptic dysfunction is amyloid beta $(A \beta)$, which self-aggregates to form the amyloid plaques that are observed in $\mathrm{AD},{ }^{5,6}$ In addition, $\mathrm{A} \beta$ contributes to suppression of basal synaptic transmission by facilitating endocytosis of $N$-methyl-D-aspartate glutamate receptors (NMDARs) and $\alpha$-amino-3-hydroxy-5-methyl-4-isoxazolepropionic acid receptors
(AMPARs) from synapses. ${ }^{7-9}$ Further, oligomers of $A \beta$ decrease the number of dendritic spines and disrupt synaptic plasticity by shifting the balance between long-term potentiation (LTP) and long-term depression (LTD). ${ }^{10}$

Neurogranin ( $\mathrm{Ng}$ or NRGN), which is widely used as a synaptic marker, is a neuron-specific postsynaptic protein that is usually expressed at dendritic spines in the cortex, hippocampus and amygdala. ${ }^{11,12}$ Additionally, $\mathrm{Ng}$ is a key molecule in synaptic plasticity and memory consolidation. ${ }^{13-15}$ For example, studies have revealed that $\mathrm{Ng}$ augmentation enhances LTP and adult hippocampal neurogenesis, leading to improvements in cognitive function. ${ }^{16-19}$ By contrast, reducing expression of $\mathrm{Ng}$ by using small hairpin RNA, Ng-null mice or $\mathrm{Ng}$ antibody-related inhibition results in LTP impairments and abnormal memory functions. ${ }^{15,16,20-24}$ However, synaptic dysfunctions induced by knockdown of $\mathrm{Ng}$ via small interfering $\mathrm{RNA}$ are restored by $\mathrm{Ng}$ overexpresion. ${ }^{19}$ Hence, it has been suggested that Ng-mediated improvements in synaptic plasticity are involved in the activation of NMDARs and insertion of AMPARs. ${ }^{19}$

\footnotetext{
${ }^{1}$ Department of Biochemistry, College of Medicine, Konyang University, Daejeon, Republic of Korea; ${ }^{2}$ Graduate School of New Drug Discovery and Development, Chungnam National University, Daejeon, Republic of Korea; ${ }^{3}$ Department of New Drug Discovery and Development, Chungnam National University, Daejeon, Republic of Korea; ${ }^{4}$ Department of Medicinal Biotechnology, College of Health Sciences, Dong-A University, Busan, Republic of Korea and ${ }^{5}$ Department of Biochemistry and Biomedical Sciences, Seoul National University College of Medicine, Seoul, Republic of Korea Correspondence: Professor M Moon, Department of Biochemistry, College of Medicine, Konyang University, Deajeon 302-718, Republic of Korea. E-mail: hominmoon@konyang.ac.kr Received 6 June 2017; revised 27 September 2017; accepted 9 October 2017
} 
Previous studies have shown that the Ng level is significantly changed in the plasma and cerebrospinal fluid (CSF) of patients with $\mathrm{AD}$ compared with that in age-matched controls, suggesting that $\mathrm{Ng}$ may be a biomarker for diagnosing $\mathrm{AD} .{ }^{25-31}$ In particular, expression of $\mathrm{Ng}$ is significantly reduced in the hippocampus and cortex of patients with $\mathrm{AD}$ as well as transgenic mouse models of AD. ${ }^{32-36}$ However, $\mathrm{Ng}$ cannot be delivered to the dendrites of neurons in brains with $\mathrm{AD}$, indicating that the $\mathrm{Ng}$ level is locally reduced at the synapse in $\mathrm{AD} .{ }^{32}$ Furthermore, a recent study demonstrated that increasing the $\mathrm{Ng}$ level rescued $\mathrm{A} \beta$-induced deficits in synaptic function, namely, deficits in LTP, and synaptic delivery of AMPARs in amyloid precursor protein (APP)expressing neurons. ${ }^{37}$ Nevertheless, to date, the pathological role that $\mathrm{Ng}$ has in the learning and memory deficits that are related to $\mathrm{AD}$ has not yet been described.

Therefore, the present study aimed to elucidate whether $\mathrm{Ng}$ expression is functionally related to cognition in an animal model of AD. Based on the existing literature, we hypothesized that reducing the $\mathrm{Ng}$ expression level in the brain parenchyma would impair cognitive function, while such impairments would not be observed after elevating the Ng levels in a mouse model of AD (5XFAD mice). Specifically, we investigated: (1) whether overexpressing Ng through hippocampal injections of a lentiviral vector elevated the levels of $\mathrm{Ng}$ in the brain and eliminated the cognitive deficits observed in SXFAD mice and (2) whether the histological mechanisms for improving cognitive functions were mediated by the enhanced $\mathrm{Ng}$ expression in 5XFAD mice.

\section{MATERIALS AND METHODS}

\section{Lentivirus production and transduction}

A lentiviral vector expressing $\mathrm{Ng}$ under the control of the mouse cytomegalovirus immediate-early promoter (pLentiM1.2-hNRGN) was constructed by inserting Ng cDNA into Sall and EcoRI restriction enzyme sites in the pLentiM1.2 plasmid. Lentiviral vector particles were produced as described previously. ${ }^{38}$ Human embryonic kidney 293T cells were cultured in Dulbecco's modified Eagle's medium (Hyclone Laboratories Inc., South Logan, UT, US) with 10\% fetal bovine serum (Gibco-BRL, Waltham, MA, USA) and maintained in a $5 \% \mathrm{CO}_{2}$ incubator at $37^{\circ} \mathrm{C}$. Lentivirus particles were produced by co-transfecting human embryonic kidney $293 \mathrm{~T}$ cells with three plasmids, VSV-G, gag-pol and pLentiM1.2-hNRGN, using Lipofectamine Plus (Invitrogen, Carlsbad, CA, USA). At $48 \mathrm{~h}$ post transfection, culture supernatants containing virus particles were collected and clarified with a $0.45-\mu \mathrm{m}$ membrane filter (Thermo Scientific, Waltham, MA, USA) and stored in a $-70^{\circ} \mathrm{C}$ deep freezer immediately. Titers were determined with p24 enzyme-linked immunosorbent assays (Perkin-Elmer Life Science, Waltham, MA, USA) or western blot analyses using a monoclonal anti-p24 antibody (obtained from the AIDS Research and Reference Reagent Program, National Institutes of Health, Bethesda, MD, USA). In our routine preparation, the titers were $\fallingdotseq 10^{7}$ transduction units (TU) $\mathrm{ml}$ without further concentration. For stereotaxic injection, the lentivirus particles were concentrated by ultracentrifugation on a $20 \%$ sucrose cushion $(2 \mathrm{~h}$ at $50000 \mathrm{~g}$ ) at $4{ }^{\circ} \mathrm{C}$. HeLa cells at $70 \%$ confluence in 6 -well plates were transduced for $8 \mathrm{~h}$ in the presence of $8 \mathrm{~g} \mathrm{ml}^{-1}$ polybrene, after which the medium was refreshed.

\section{Western blotting}

Human embryonic kidney 293 cells were lysed using a Protein Assay Kit (Thermo Scientific) according to the manufacturer's instructions. The lysates were separated by $10 \%$ sodium dodecyl sulfatepolyacrylamide gel electrophoresis and transferred to a nitrocellulose membrane. The membranes were incubated with blocking solution (5\% skim milk in Tris-buffered saline with $0.05 \%$ Tween-20) for $1 \mathrm{~h}$ and then incubated with a blocking solution containing a primary antibody (Ng (Abcam, Cambridge, UK) 1:1000; $\beta$-actin (SigmaAldrich, St. Louis, MO, USA) 1:5000) overnight at $4{ }^{\circ} \mathrm{C}$. The membranes were incubated with a horseradish peroxidaseconjugated secondary antibody for $1 \mathrm{~h}$. Immunoreactive bands were detected using an enhanced chemiluminescence western blotting substrate (Thermo Scientific).

\section{Animals}

Adult male C57BL/6 mice (7 weeks old) were obtained from Koatech (Pyeongtaek, South Korea) and acclimatized for 1 week before stereotaxic surgery. Experimental procedures were reviewed and approved by the Institutional Animal Care and Use Committee at Konyang University. Animals were housed in accordance with the Guide for the Care and Use of Experimental Animals (National Research Council, Eighth edition). Mice with five familial $\mathrm{AD}$ mutations (5XFAD; B6SJL-Tg [APP-SwFILon, PS1 ${ }^{\star}$ M146L ${ }^{\star}$ L286V] $6799 \mathrm{Vas} / \mathrm{J}$ ) were purchased from the Jackson Laboratory (Bar Harbor, ME, USA) and maintained by mating them with B6/SJL F1 breeder mice. 5XFAD transgenic mice were confirmed by polymerase chain reaction, and non-transgenic littermate mice were used as wild-type controls. The animal maintenance and treatment protocols were performed in accordance with the Principles of Laboratory Animal Care (National Institutes of Health Publication No. 85-23, 1985 edition) and the Animal Care and Use Guidelines of Seoul National University (Seoul, Korea).

\section{Stereotaxic injection}

Male 5XFAD and wild-type littermate mice (6 months old) were used for all investigations. Stereotaxic injection procedures were performed on anesthetized mice by using a mixture of Zoletil 50 and Rompun (3:1 ratio, $1 \mathrm{mg} \mathrm{kg}^{-1}$, intraperitoneally). A solution containing Ng-green fluorescent protein (GFP) lentivirus $\left(1 \times 10^{7}\right.$ in $2 \mu \mathrm{l})$ was injected into the hilus of the dentate gyrus of the hippocampus $(-2.0 \mathrm{~mm}$ anterior-posterior, $1.3 \mathrm{~mm}$ medial-lateral, and $-1.9 \mathrm{~mm}$ dorsal-ventral relative to the bregma) using a Hamilton syringe at a rate of $0.2 \mu \mathrm{min}^{-1}$. After the injection, we let the needle rest in place for $8 \mathrm{~min}$ to prevent regurgitation of the virus during removal. Control groups were injected with the same volume of control lentivirus.

\section{Y-maze test}

The Y-maze apparatus was composed of three divided passages, with each arm $8 \mathrm{~cm}$ wide, $30 \mathrm{~cm}$ long and $15 \mathrm{~cm}$ high. To determine the rates of spontaneous alternation, each mouse was allowed to explore the maze for $8 \mathrm{~min}$. Spontaneous alternation was defined as successive entries into three different passages without repetition (e.g., $A B C$ or $\mathrm{BCA}$ but not $\mathrm{ABA})$. The spontaneous alternation percentage was calculated using the following equation: number of alternations/(total number of arm entries-2) $\times 100$. 
a
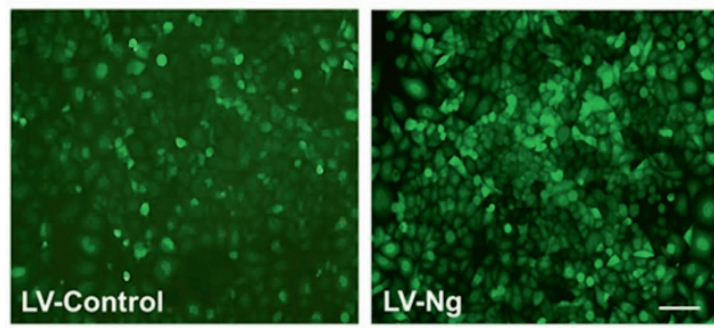

C
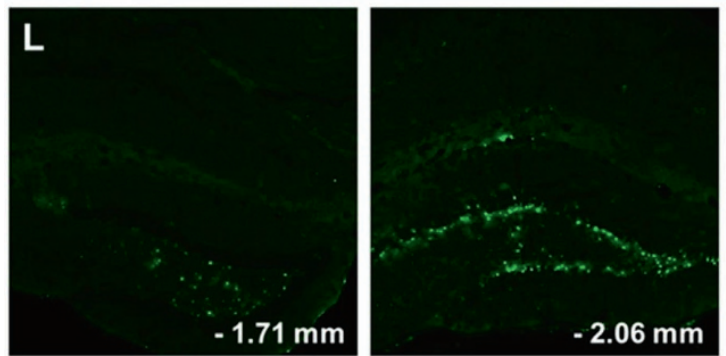

Anterior

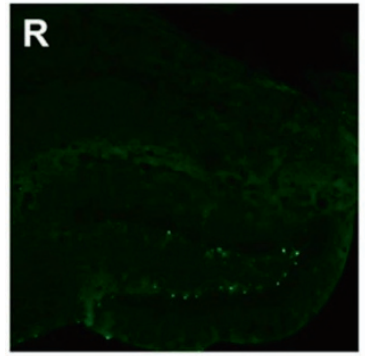

d
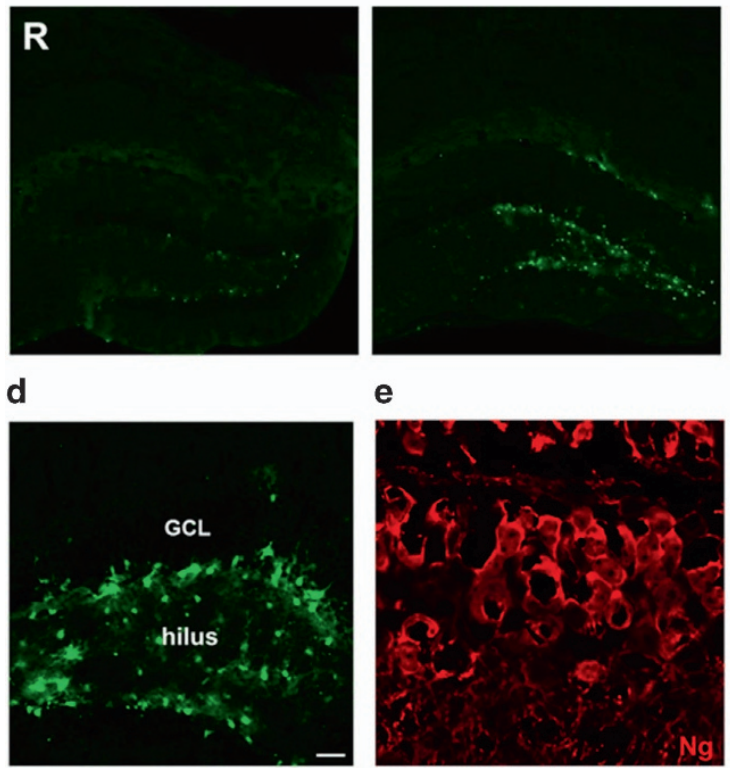

e

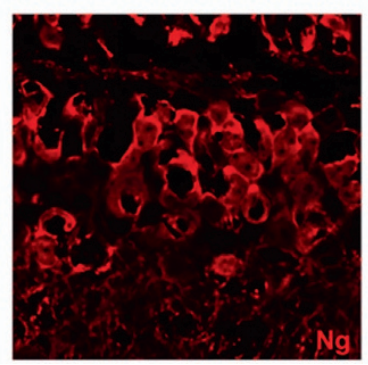

b
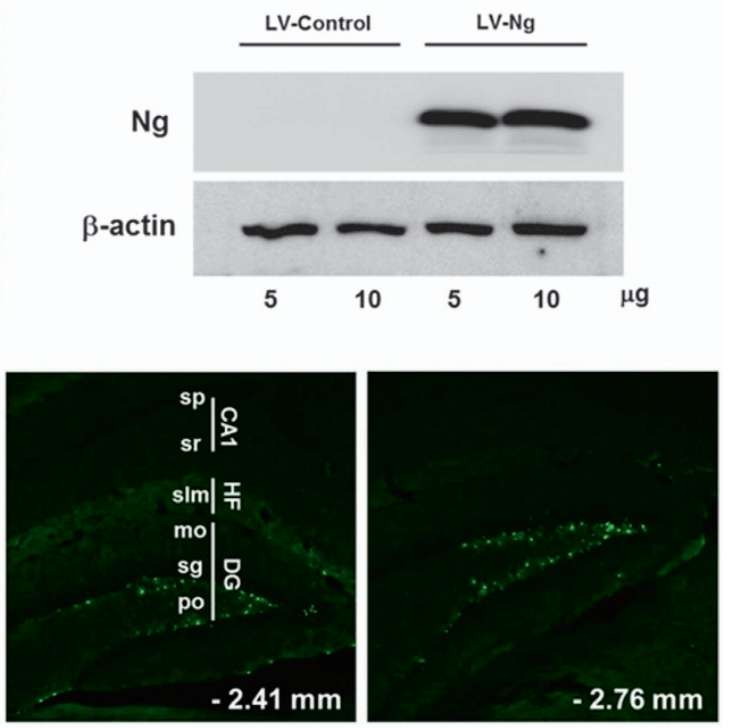

$0.35 \mathrm{~mm}$ interval
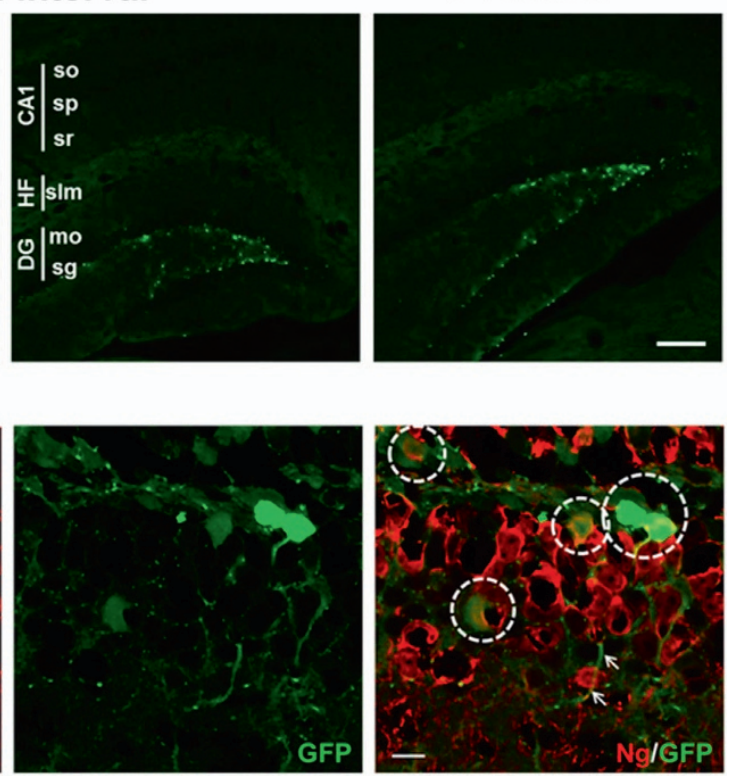

Figure 1 Expression of green fluorescent protein (GFP) and GFP-neurogranin (GFP-Ng) in cells transduced by a lentiviral vector. (a) Detection of GFP after transduction of LentiM1.2 (empty vector) (LV-control) or LentiM1.2-Ng (LV-Ng) in HeLa cells. Scale bar $=100 \mu \mathrm{m}$. (b) Western blot analysis exhibited Ng expression in lysates from HeLa cells transduced with LV-Ng. The anatomical spread of LV-GFP-Ng in C57BL/6 mice is seen in (c-e). (c) Examination of GFP expression in hippocampal sections obtained at $0.35 \mathrm{~mm}$ intervals. Scale bar $=200 \mu \mathrm{m}$. (d) GFP expression in the hilus and dentate gyrus of a C57BL/6 mouse injected with LV-GFP-Ng. Scale bar $=60 \mu \mathrm{m}$. (e) Localization of $\mathrm{Ng}$ - and GFP-expressing cells in the dentate gyrus. The white circles and arrows indicate the GFP-expressing somata and neurites, respectively. Scale bar $=20 \mu \mathrm{m}$. DG, dentate gyrus; GCL, granule cell layer; HF, hippocampal fissure; mo, molecular layer; po, polymorph layer; sg, granule cell layer; slm, stratum lacunosum moleculare; so, stratum oriens; sp, pyramidal layer; sr, stratum radiatum.

\section{Novel object recognition test}

The novel object recognition test was executed in an open field box $\left(50 \times 50 \times 50 \mathrm{~cm}^{3}\right)$. Before the test, mice were habituated in the test box for 5 min without objects. After habituation, each mouse was placed in the test box and permitted to explore two identical objects (familiarization session) for $5 \mathrm{~min}$. Twenty-four hours after the familiarization session, each mouse was permitted to explore both the familiar object and a novel object (test session) for $5 \mathrm{~min}$. In the test session, the objects used were wooden blocks of the same scale but of different shape. The time spent exploring each object was recorded and analyzed using a video tracking system (Noldus, Wageningen, Netherlands).

\section{Brain tissue preparation}

Mice were anesthetized and transcardially perfused with $0.05 \mathrm{M}$ phosphate-buffered saline and then fixed with ice-cold $4 \%$ paraformaldehyde in $0.1 \mathrm{~m}$ phosphate buffer. The brain was removed and 

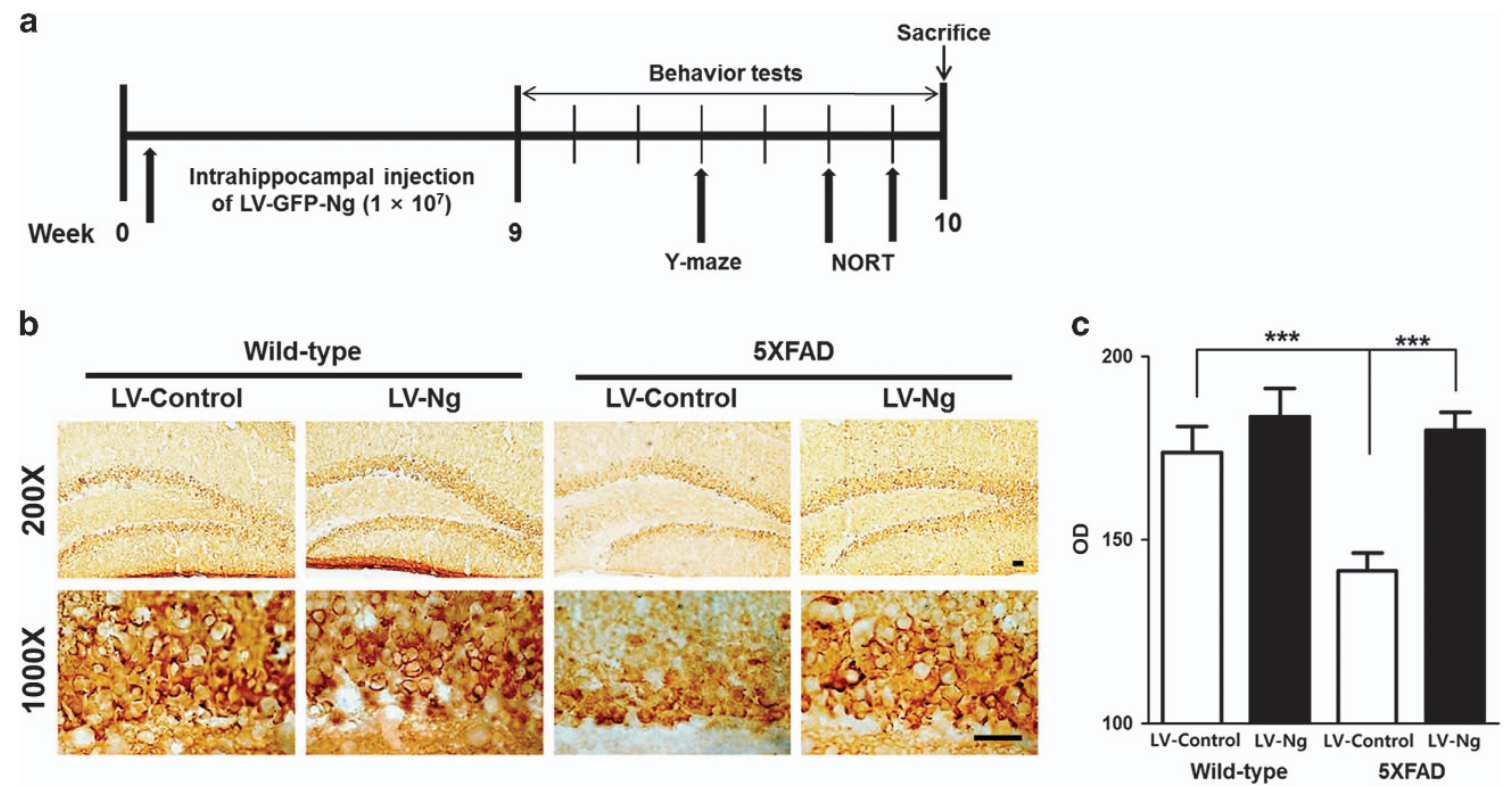

Figure 2 Hippocampal injection of LentiM1.2-Ng (LV-Ng) compensated for the reduction in neurogranin (Ng) expression in the hippocampus of 5XFAD mice. (a) Experimental scheme for the behavioral studies and stereotaxic surgery. Behavioral tests were performed 9 weeks after surgery, and animals were killed 10 weeks after stereotaxic injection. (b) Representative images of $\mathrm{Ng}$ expression in the dentate gyrus of the hippocampus. LentiM1.2 (empty vector) (LV-control)-injected 5XFAD mice showed less immunoreactivity compared with their wild-type littermates. The LV-Ng-injected groups exhibited elevated Ng immunoreactivity in the brains of 5XFAD and wild-type mice. Scale bars $=50 \mu \mathrm{m}$. (c) Immunoreactivity of $\mathrm{Ng}$ was statistically analyzed by one-way analysis of variance (ANOVA) followed by Fisher's least significant difference $(\mathrm{LSD})$ test $(\mathrm{F}(3,60)=9.272, P=0.0129) .{ }^{* * *} P<0.001$.

postfixed in $0.1 \mathrm{M}$ phosphate buffer containing $4 \%$ paraformaldehyde for $20 \mathrm{~h}$ at $4{ }^{\circ} \mathrm{C}$ and then soaked in a solution containing $30 \%$ sucrose in $0.05 \mathrm{M}$ phosphate-buffered saline for cryoprotection at $4{ }^{\circ} \mathrm{C}$. Serial coronal sections (30- $\mu$ m-thick) were cut on a cryomicrotome and stored in cryoprotectant $(25 \%$ ethylene glycol and $25 \%$ glycerol in $0.05 \mathrm{M}$ phosphate buffer) at $4{ }^{\circ} \mathrm{C}$ until immunohistochemical analysis.

\section{Immunoperoxidase and immunofluorescence staining}

For immunohistochemical analyses, brain sections were rinsed briefly in phosphate-buffered saline and treated with $1 \%$ hydrogen peroxide for $15 \mathrm{~min}$. The sections were incubated with a goat anti-Ng antibody (1:500; Abcam) or anti-postsynaptic density protein-95 (PSD-95) antibody (1:500; Abcam). The sections were next incubated with a biotinylated horse anti-goat immunoglobulin G (1:200; Vector Laboratories, Burlingame, CA, USA) and avidin-biotin-peroxidase complex solution and then visualized with a SIGMA FAST ${ }^{\mathrm{TM}} 3.3^{\prime}$ diaminobenzidine tablet (Sigma-Aldrich) as a chromogen. To quantify the immunoreactivity of PSD-95, the images were analyzed using the Image-Pro Plus 6.0 program (Media Cybernetics, Rockville, MD, USA). For immunofluorescence staining, brain sections were rinsed briefly in phosphate-buffered saline and incubated with a goat anti-Ng antibody $\left(1: 500,4{ }^{\circ} \mathrm{C}, 12 \mathrm{~h}\right)$ followed by donkey anti-goat Alexa Fluor ${ }^{\circ}$ 594 immunoglobulin G (1:200, room temperature, 1 h; Abcam). All sections were counter-stained with 4',6-diamidino-2-phenylindole (Thermo Scientific) before mounting.

\section{Statistical analysis}

Data are presented as the mean \pm the standard error of the mean. For the Y-maze test and immunohistochemical data, the significance of differences between the four groups was defined by one-way analysis of variance, followed by the Fisher's least significant difference post hoc test using SigmaPlot for Windows Version 12.2 (Systat Software Inc., CA, USA). In the novel object recognition test, differences between two groups were analyzed with Student's unpaired $t$-tests in GraphPad Prism 5 (GraphPad Software Inc., La Jolla, CA, USA). Statistical significance was set at $P<0.05$.

\section{RESULTS}

Ability of the lentiviral vector to induce $\mathrm{Ng}$ and GFP expression

Using immunoblot analyses, we investigated $\mathrm{Ng}$ expression in HeLa cells after transduction with pLentiM1.2-hNRGN. As shown in Figure 1, expression of human $\mathrm{Ng}$ was detected 2 days after infection. To evaluate the transduction efficiency of the Ng-expressing lentiviral vector (pLentiM1.2-hNRGN), cDNA of human $\mathrm{Ng}$ was inserted into a lentiviral vector (pLentiM1.2) encoding the GFP gene, which is expressed through internal ribosome entry site sequences. As expected, we observed GFP expression in HeLa cells transduced with pLentiM1.2-hNRGN lentiviral vector particles (Figure 1a). Identification of $\mathrm{Ng}$ protein by western blot in transduced HeLa cells show $\mathrm{Ng}$ expression in both 5 and $10 \mathrm{~g}$ of cell lysates (Figure 1b).

\section{Ability of the lentiviral vector to deliver $\mathrm{Ng}$ to the mouse brain}

In addition to the above in vitro test, we investigated gene expression mediated by the lentivirus-GFP-Ng in vivo. To do so, we injected $2 \mu \mathrm{l}$ of titrated virus $\left(5 \times 10^{6}\right)$ into the hilus of the dentate gyrus of adult C57BL/6 mice ( 8 weeks old). At 14 days after infection, we confirmed GFP expression in the 

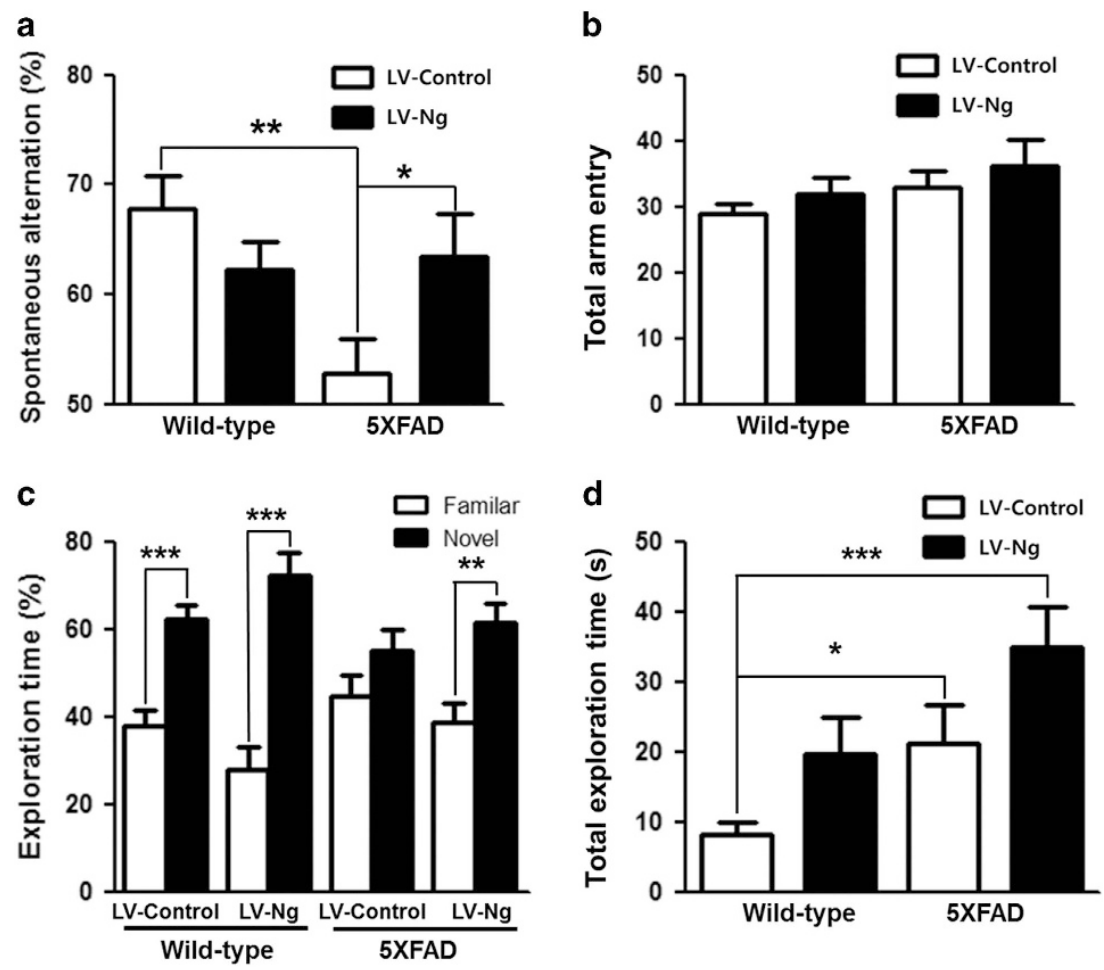

Figure 3 Mice with enhanced neurogranin ( $\mathrm{Ng}$ ) expression had fewer cognitive dysfunctions than 5XFAD mice. (a) One-way analysis of variance (ANOVA) followed by Fisher's least significant difference (LSD) test indicated that 5XFAD mice exhibited significantly fewer spontaneous alterations compared to their wild-type littermates (shown by **), and LentiM1.2-Ng (LV-Ng)-injected 5XFAD mice ( $n=7-8$ ) exhibited significantly more spontaneous alternations compared to LentiM1.2 (empty vector) (LV-control)-injected 5XFAD mice (shown by $\left.{ }^{*}\right)$ in the $Y$-maze test $(F(3,25)=3.679, P=0.025)$. No significant difference in spontaneous alternations was noted between the LV-control- and LV-Ng-injected wild-type littermate mice. (b) The number of total arm entries was not significantly different between the groups. (c) A significant difference between the familiar object and novel object explorations times was found for LV-Ng-injected 5XFAD mice. (d) The total exploration time indicated that LV-Ng injection did not significantly increase the exploration time in wild-type and 5XFAD mice compared with that in LV-control-injected mice. Error bars indicate the standard error of the mean. ${ }^{*} P<0.05,{ }^{*} P<0.01$ and $* * * P<0.001$

dentate gyrus of mice. Indeed, GFP was detected in the hilus and granule cell layers of brains injected with lentivirus-GFPNg. The virus-injected brain sections $(0.35-\mathrm{mm}$ intervals) displayed widespread expression of GFP from the injection site to the entire hippocampus (Figure 1c and Supplementary Figure 1). Magnified images confirmed the robust and specific expression of GFP in the dentate gyrus transduced with lentivirus (Figure 1d). Additionally, images obtained under high magnification showed that virus-infected brains exhibited colocalization of Ng and GFP in the dentate gyrus (Figure 1e). These results confirmed that $\mathrm{Ng}$ overexpression was successfully established through lentiviral gene delivery in vivo.

Hippocampal injection of lentivirus- $\mathrm{Ng}$ ameliorates the reduction of $\mathrm{Ng}$ expression observed in 5XFAD mice It is well known that $\mathrm{Ng}$ expression is reduced in the hippocampus and cortex of brains with AD. ${ }^{32-36}$ Therefore, we investigated whether the intrahippocampal injection of the Ng-containing lentiviral vector into 5XFAD mice would elevate the otherwise reduced $\mathrm{Ng}$ level. The brains were histologically analyzed at 10 weeks after lentivirus injection (Figure 2a). Immunohistochemical examinations demonstrated that lentivirus-Ng-injected 5XFAD mice had elevated $\mathrm{Ng}$ expression compared to 5XFAD mice injected with the control lentivirus (Figure $2 \mathrm{~b}$ ) and increased $\mathrm{Ng}$ immunoreactivity was statistically significant (Figure 2c). These data suggest that overexpressing $\mathrm{Ng}$ via gene transfer may compensate for the downregulated $\mathrm{Ng}$ expression that is observed in brains with AD.

$\mathrm{Ng}$ overexpression improves the cognitive dysfunctions observed in 5XFAD mice

Several previous reports have shown that increasing the $\mathrm{Ng}$ expression level significantly enhances LTP as well as memory and learning abilities. ${ }^{16-19}$ In addition, increasing the $\mathrm{Ng}$ level has been shown to restore the $\mathrm{A} \beta$-induced synaptic depression and LTP deficits in hippocampal slices. ${ }^{37}$ Here, we examined whether the lentivirus-Ng injection influenced the cognitive behaviors of 5XFAD mice, a transgenic animal with $A \beta$ overexpression. First, we analyzed the animals' short-term and working memory by using the Y-maze test. We found that 5XFAD mice exhibited significantly fewer spontaneous alterations compared to their wild-type littermates (Figure 3a). However, 5XFAD mice that overexpressed $\mathrm{Ng}$ after the 
hippocampal injection of lentivirus- $\mathrm{Ng}$ displayed significantly more spontaneous alternations compared to 5XFAD mice injected with the control lentivirus (Figure 3a). To identify whether the memory enhancements observed following $\mathrm{Ng}$ overexpression were related to changes in locomotor activity, we compared the total number of arm entries between the groups. No significant difference was noted between the experimental groups (Figure 3b). Second, we analyzed animals' long-term recognition memory by using the novel object recognition test. The time spent exploring the novel object vs. familiar object was not significantly different in lentiviruscontrol-injected 5XFAD mice (Figure 3c). After injecting 5XFAD mice with lentivirus- $\mathrm{Ng}$, the novel object vs. familiar object exploration times were significantly different (Figure 3c). No significant difference in total exploration time was identified between lentivirus-control- and lentivirus-Ng-injected 5XFAD mice (Figure 3d). These findings suggest that elevating $\mathrm{Ng}$ expression through a hippocampal lentivirus-Ng injection can significantly reduce the amount of cognitive decline that occurs in $5 \mathrm{XFAD}$ mice.

\section{Enhancing Ng expression induces PSD-95 expression in the hippocampus of 5XFAD mice}

Recently, it was reported that $\mathrm{Ng}$ overexpression reverses the $\mathrm{A} \beta$-mediated deficits in synaptic transmission and LTP through calmodulin (CaM)-calcium/calmodulin-dependent protein kinase II (CaMKII)-mediated insertion of a new GluA1-containing AMPAR into the postsynaptic domain. ${ }^{37}$ Moreover, it has been shown that PSD-95 acts as a slot protein for AMPAR by stabilizing it in the synapse and that overexpression of PSD-95 selectively promotes synaptic accumulation of AMPARs. ${ }^{39-42}$ Therefore, we investigated whether the Ng-mediated improvements in cognition that we observed were associated with PSD-95 expression. Immunohistochemical analysis of PSD-95 expression revealed that the optical density value of lentivirus-Ng-injected 5XFAD mice was significantly higher than that of lentivirus-control-injected 5XFAD mice (Figure 4). Our results indicated that the hippocampal injection of lentivirus-Ng significantly elevated PSD-95 expression in the hippocampus of 5XFAD mice.

\section{DISCUSSION}

To date, the role that $\mathrm{Ng}$ has in $\mathrm{AD}$-related memory impairment has not been studied. Here, we locally injected a lentivirus containing GFP-Ng into the hippocampus of wild-type and 5XFAD mice. Our data demonstrated that: (1) expression of $\mathrm{Ng}$ was reduced in the dentate gyrus of 5XFAD mice and (2) $5 \mathrm{XFAD}$ mice injected with lentivirus- $\mathrm{Ng}$ had higher $\mathrm{Ng}$ expression compared to that in mice injected with control lentivirus. Furthermore, the augmented expression of $\mathrm{Ng}$ contributed to the enhancement of cognitive functions and PSD-95 expression in this animal model of AD. Collectively, these results suggest that reduced $\mathrm{Ng}$ levels may lead to the cognitive decline observed in $\mathrm{AD}$, and thus supplementation with $\mathrm{Ng}$ may be a potent therapeutic strategy for this disease.
Many reports have demonstrated that the $\mathrm{Ng}$ expression levels are significantly changed in the CSF, serum and brain parenchyma of individuals with $\mathrm{AD}$. More specifically, $\mathrm{Ng}$ expression is downregulated in the brain parenchyma of the frontal cortex and hippocampus in animal models and patients with AD. ${ }^{32-36}$ By contrast, the $\mathrm{Ng}$ level in the CSF is elevated in $\mathrm{AD} \cdot{ }^{27,30,43,44}$ It has been suggested that the observed increase in $\mathrm{CSF} \mathrm{Ng}$ in $\mathrm{AD}$ might be related to widespread synaptic degeneration or $A \beta$-dependent neurodegeneration. ${ }^{27,43-45}$ In other words, abundant $\mathrm{Ng}$ in the dendritic spines may leak into the CSF as the disease progresses. Interestingly, this elevation in the dendritic protein $\mathrm{Ng}$ is specific to $\mathrm{AD}$ and has not been observed in other neurodegenerative diseases, including a range of dementias, synucleinopathies and tauopathies. ${ }^{31}$ Apolipoprotein (APO) $\varepsilon 4$ carriers are commonly recognized as a high-risk group for $\mathrm{AD}$ development owing to their susceptibility to synaptic damage, ${ }^{46}$ and a high $\mathrm{Ng}$ level demonstrates early synaptic damage in apolipoprotein $\varepsilon 4$ carriers. ${ }^{47}$ Additionally, the CSF $\mathrm{Ng} / \mathrm{\beta a}$-secretase 1 ratio is an indicator of cognitive impairments in $\mathrm{AD}$ and Lewy body dementia. ${ }^{48,49}$ Taken together, the existing evidence clearly supports that the $\mathrm{Ng}$ levels are correlated with the A $\beta$-mediated synaptic degeneration and cognitive decline that occur in $\mathrm{AD}$ and suggests that $\mathrm{Ng}$ may be a predictive marker for disease progression or synaptic degeneration in AD. However, to our knowledge, no study has provided direct evidence regarding whether $\mathrm{Ng}$ expression is associated with cognitive behaviors in $\mathrm{AD}$.

To monitor the pathology of $\mathrm{AD}$, neuroimaging methods, such as positron emission tomography and magnetic resonance imaging, and CSF biochemical makers, such as A $\beta$ and tau, are widely used. ${ }^{50}$ Unfortunately, no biomarkers that can directly monitor synaptic dysfunction in $\mathrm{AD}$ are currently available. Based on our findings, we believe that $\mathrm{Ng}$ has the potential to be a prognostic marker for both histological and biochemical analyses in patients with $\mathrm{AD}$.

It is known that $A \beta$ results in the blockade of LTP, synaptic depression and spine shrinkage. According to the A $\beta$ hypothesis, mutations in APP and presenilin 1 may result in overproduction of $\mathrm{A} \beta$. Here, we used $5 \mathrm{XFAD}$ mice as an $\mathrm{A} \beta$-overexpressing animal model of $\mathrm{AD}$ (Supplementary Figure 2) since these mice overexpress the human APP 695 mutation (Swedish (K670N, M671L), Florida (I716V) and London (V717I)), and human presenilin 1 mutation (M146L and L286V). Transgenes were controlled according to the neuron-specific Thyl promoter. Importantly, 5XFAD mice exhibit $\mathrm{AD}$-related pathologies, such as $\mathrm{A} \beta$ accumulation inside the neuron, LTP/long-term depression deficits, A $\beta$-mediated synaptic loss and cognitive decline. ${ }^{51-53}$

Prior studies have revealed that $\mathrm{A} \beta$ accumulation via selfaggregation is the main causative agent of $\mathrm{AD}$ pathogenesis. Soluble A $\beta$ oligomers are known to induce an imbalance between LTP and long-term depression, reduce the number of dendritic spines and suppress basal transmission. ${ }^{1}$ When postsynaptic glutamate receptor ion currents are disrupted, NMDARs and AMPARs are removed from the synapse 
a
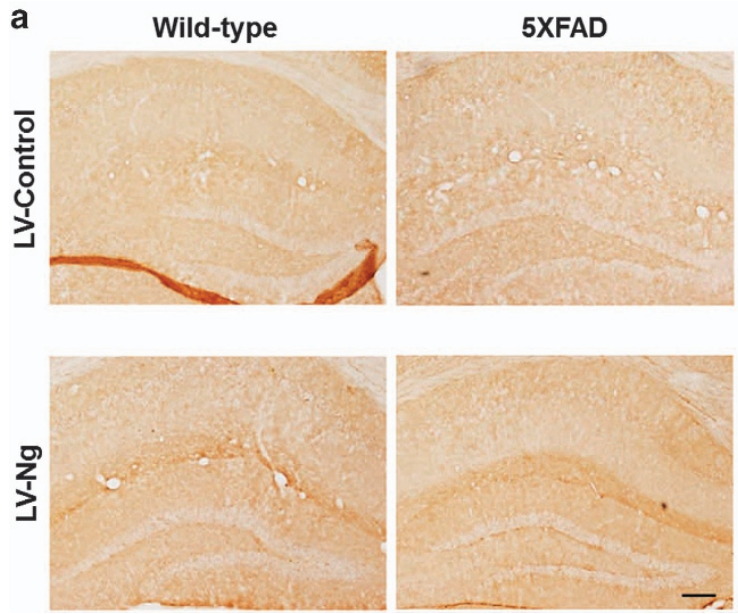

b

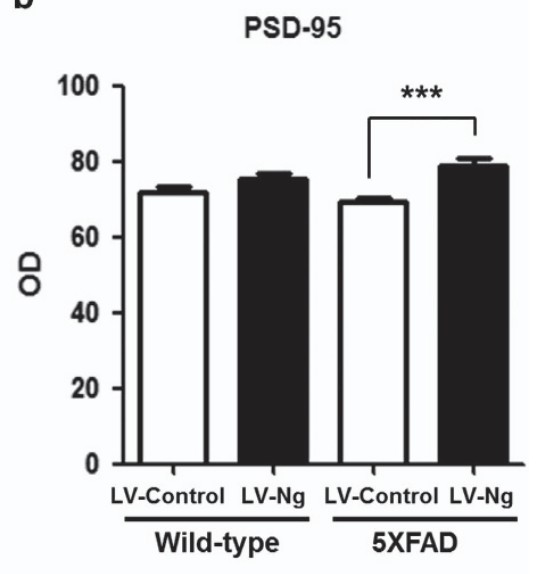

Figure 4 Enhancing neurogranin (Ng) expression in 5XFAD mice upregulated postsynaptic density protein-95 (PSD-95) expression. (a) Immunohistochemical analyses were performed with the anti-PSD-95 antibody in the brains of 5XFAD and wild-type mice. (b) One-way analysis of variance (ANOVA) followed by Fisher's least significant difference (LSD) test showed that LentiM1.2-Ng (LV-Ng) injection significantly increased the optical density of PSD-95 immunoreactivity in the hippocampus of 5XFAD mice compared to that of LV-controlinjected 5XFAD mice (shown by ${ }^{* * *} ; \mathrm{F}(3,24)=17.098, P=0.0082$ ). Error bars indicate the standard error of the mean. ${ }^{* * *} P<0.001$. Scale bar $=100 \mu \mathrm{m}$.

through endocytosis. ${ }^{9,54,55} \mathrm{~A} \beta$ has also been shown to lead to AMPAR removal and spine loss. ${ }^{55}$ Additionally, A $\beta$-mediated synaptic failure is dependent on NMDAR inactivation. Interestingly, $\mathrm{Ng}$ is known to enhance synaptic plasticity independent of AMPAR activation and NMDAR insertion. ${ }^{19,37}$ While blockade of CaMKII autophosphorylation is a major mechanism that is involved in $\mathrm{A} \beta$-induced synaptic dysfunction, $\mathrm{Ng}$ induced synaptic enhancement requires autophosphorylation of CaMKII. ${ }^{56,57}$

$\mathrm{Ng}$ is a substrate of protein kinase $\mathrm{C}$ (PKC), which controls $\mathrm{CaM}$ signaling, thus allowing it to influence synaptic and cognitive functions. Reduced $\mathrm{Ng}$ expression results in LTP impairment and abnormal cognitive functions. ${ }^{15,16,20-24}$ Moreover, the loss of $\mathrm{Ng}$ reduces the AMPAR-positive synapse numbers, inhibits AMPAR-silent synapse maturation, enhances spine elimination and produces sensitization of long-term depression. ${ }^{24}$ By contrast, increasing the $\mathrm{Ng}$ levels enhances LTP and memory functions. ${ }^{16-19}$ Since $\mathrm{Ng}$ augmentation can enhance synaptic and cognitive functions in healthy brains, here we examined whether $\mathrm{Ng}$ was also able to improve cognitive behaviors in an animal model of AD. Previous studies demonstrated that $\mathrm{Ng}$ regulates synaptic plasticity and reinforcement by inserting the GluA1-containing AMPAR into the synapse during $\mathrm{A} \beta$-mediated synaptic degeneration through conversion of CaM and CaMKII. ${ }^{37}$ In addition, PSD-95 is necessary for the insertion, stabilization and accumulation of AMPARs in the synapse, ${ }^{39,42,58}$ which in turn strengthens LTP and increases excitatory postsynaptic currents. ${ }^{37}$ Thus, we speculate that the increase in $\mathrm{Ng}$ that we produced by injecting lentivirus-Ng into the hippocampus upregulated PSD-95 and induced AMPAR insertion. Moreover, PSD-95 may help anchor AMPARs in the synapse, ultimately increasing the postsynaptic density and inducing excitatory postsynaptic currents and LTP (Figure 5).
In $\mathrm{AD}$, the memory deficits caused by $\mathrm{A} \beta$ are partially related to synaptic dysfunctions, including synaptic depression and LTP inhibition. Interestingly, a recent study reported that $\mathrm{Ng}$, a postsynaptic CaM-targeting protein, restored the deficits in synaptic transmission and LTP in A $\beta$-treated hippocampal slices. ${ }^{37}$ It has also been shown that $\mathrm{A} \beta$-induced depression of synaptic transmission is caused by the removal of AMPARs. Surprisingly, $\mathrm{Ng}$ can prevent $\mathrm{A} \beta$ from removing AMPARs and lead to the insertion of AMPARs, as was observed in animals that expressed $\mathrm{APP}_{\text {swe }}$ and underwent $\mathrm{A} \beta$ treatment. ${ }^{37}$ However, evidence regarding whether $\mathrm{Ng}$ can restore the cognitive behaviors in $\mathrm{A} \beta$-overexpressing animal models of $\mathrm{AD}$ is lacking. To the best of our knowledge, our study is the first to demonstrate that $\mathrm{Ng}$ can improve $\mathrm{A} \beta$-mediated memory deficits in an animal model of AD.

To investigate whether $\mathrm{Ng}$ overexpression affects $\mathrm{A} \beta$ deposition, amyloid plaques in the hippocampus of 5XFAD mice were detected using an anti-A $\beta$ antibody (Supplementary Figure 3). In LV-Ng-injected 5XFAD mice, the plaque load was not changed compared with that of LV-control-injected 5XFAD mice. These data suggest that $\mathrm{Ng}$ overexpression ameliorated the impairment of cognitive functions without influencing $\mathrm{A} \beta$ pathology in 5XFAD mice. Moreover, our findings suggest that $\mathrm{A} \beta$-mediated downregulation of $\mathrm{Ng}$ may be the cause of the memory impairments in $\mathrm{AD}$. In the novel object recognition test, we found that the total exploration time of 5XFAD mice was significantly longer than that of wild-type mice. However, no significant differences were observed between the lentivirus-Ng- and lentivirus-control-injected groups in either wild-type or 5FXAD mice. In 5XFAD mice, despite the significant elevation in the total exploration time, the exploration time for novel objects was significantly shorter. Altogether, our data from the novel object recognition test 


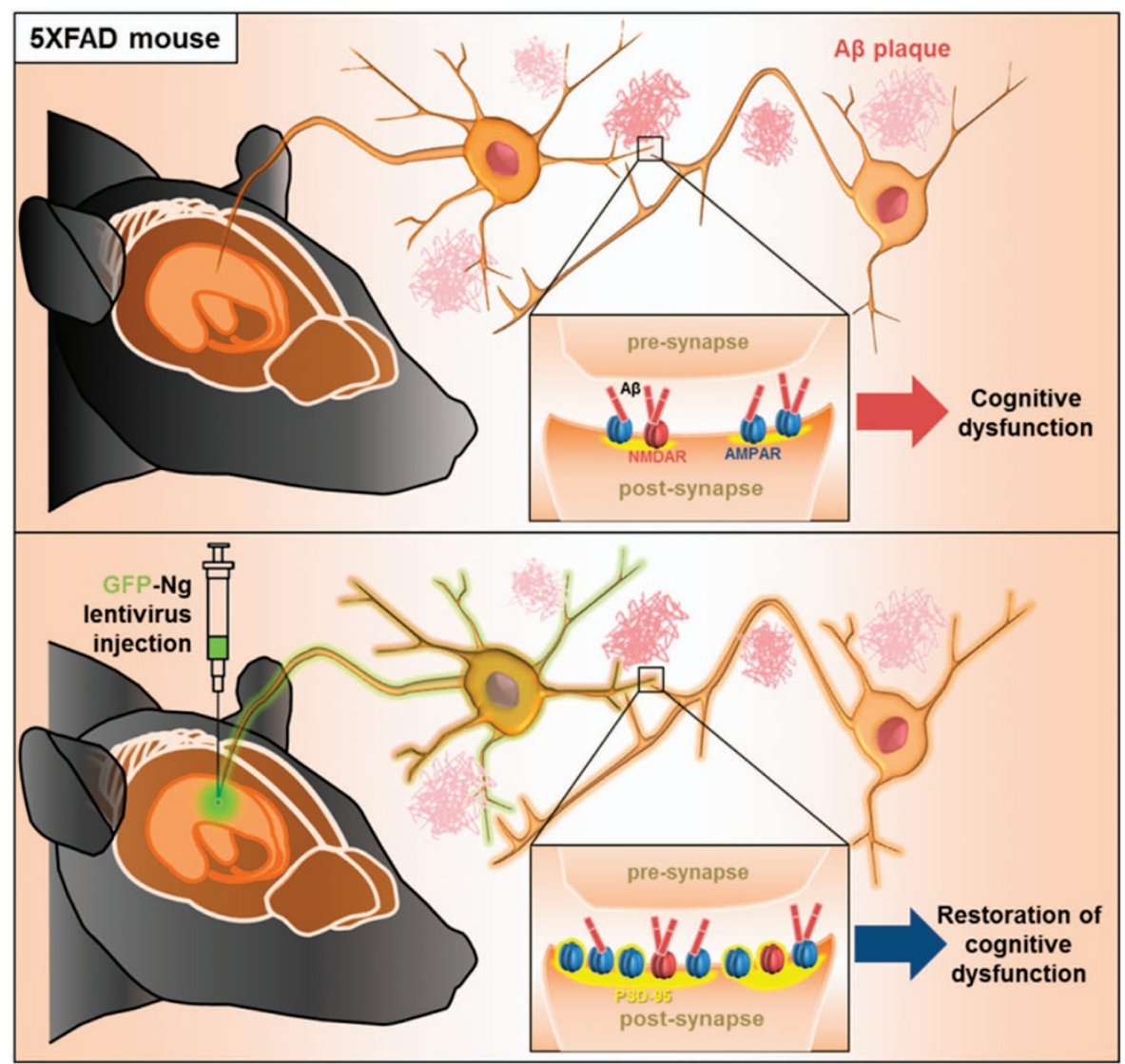

Figure 5 Potential memory enhancement mechanisms mediated by the overexpression of neurogranin ( $\mathrm{Ng}$ ) in amyloid beta $(\mathrm{A} \beta)$ overexpressing mice. The overexpressed $A \beta$ leads to synaptic failure in the brains of 5XFAD mice. The fewer cognitive deficits we observed in LentiM1.2-Ng (LV-Ng)-injected 5XFAD mice may result either from the blockade of A $\beta$-induced depression in synaptic transmission or from the insertion of $\alpha$-amino-3-hydroxy-5-methyl-4-isoxazolepropionic acid receptors (AMPARs). Enhancing the expression of $\mathrm{Ng}$ may stimulate the ionotropic glutamate receptor signaling pathways, such as the $\mathrm{Ca}^{2+}$-dependent activation of calcium/calmodulin-dependent protein kinase II (CaMKII), leading to the postsynaptic insertion of AMPARs. It is likely that Ng may reverse the A $\beta$-mediated deficits in long-term potentiation.

show that animals with upregulated $\mathrm{Ng}$ expression exhibited better cognitive performance than 5XFAD mice.

A number of studies has shown that $\mathrm{Ng}$ overexpression enhances cognitive functions by regulating synaptic plasticity ${ }^{16,18,19}$ and that enhancing synaptic plasticity increases adult hippocampal neurogenesis. ${ }^{17,59,60}$ In addition, it has been suggested that upregulation of $\mathrm{Ng}$ expression may contribute to neuronal growth and differentiation. ${ }^{61}$ Therefore, further studies are needed to investigate the neurogenic effects of $\mathrm{Ng}$ on adult hippocampal neurogenesis, one of the major mechanisms underlying the enhancement of cognitive functions. Likewise, the molecular mechanisms of Ng-mediated PSD-95 upregulation remain to be elucidated.

In summary, our results indicated that (1) expression of $\mathrm{Ng}$ was reduced in the dentate gyrus of 5XFAD mice compared with wild-type littermates, (2) 5XFAD mice with increased levels of $\mathrm{Ng}$ showed less $\mathrm{A} \beta$ overexpression-related cognitive dysfunction than 5XFAD mice and (3) overexpression of $\mathrm{Ng}$ through lentiviral transfer of the $\mathrm{Ng}$ gene enhanced expression of PSD-95 in the dentate gyrus of 5XFAD mice.
Collectively, our data suggest that the cognitive dysfunctions caused by $\mathrm{A} \beta$ may be partially associated with reductions in $\mathrm{Ng}$ expression. Such findings imply that $\mathrm{Ng}$ supplementation may be a future therapeutic strategy for enhancing cognitive functions in $\mathrm{AD}$.

\section{CONFLICT OF INTEREST}

The authors declare no conflict of interest.

\section{ACKNOWLEDGEMENTS}

This work was supported by grants from the Basic Science Research Program through the National Research Foundation of Korea (NRF) funded by the Ministry of Science, ICT and Future Planning (NRF-2015R1C1A1A01052732); Korea Health Technology R\&D Project through the Korea Health Industry Development Institute, funded by the Ministry of Health \& Welfare, Republic of Korea (HI16C0816); and Korea Foundation for the Advancement of Science and Creativity funded by the Ministry of Education to MM. This work was also supported by a grant from the NRF (2014M3A9B6073507) to Y-SK. 


\section{PUBLISHER'S NOTE}

Springer Nature remains neutral with regard to jurisdictional claims in published maps and institutional affiliations.

1 Querfurth HW, LaFerla FM. Alzheimer's disease. N Eng/ J Med 2010; 362 329-344.

2 Masliah E, Mallory M, Alford M, DeTeresa R, Hansen LA, McKeel DW Jr et al. Altered expression of synaptic proteins occurs early during progression of Alzheimer's disease. Neurology 2001; 56: 127-129.

3 Bertoni-Freddari C, Fattoretti P, Casoli T, Caselli U, Meier-Ruge W. Deterioration threshold of synaptic morphology in aging and senile dementia of Alzheimer's type. Anal Quant Cytol Histol 1996; 18: 209-213.

4 DeKosky ST, Scheff SW. Synapse loss in frontal cortex biopsies in Alzheimer's disease: correlation with cognitive severity. Ann Neurol 1990; 27: 457-464.

5 Shankar GM, Walsh DM. Alzheimer's disease: synaptic dysfunction and Abeta. Mol Neurodegener 2009; 4: 48.

6 Selkoe DJ. Alzheimer's disease is a synaptic failure. Science 2002; 298 789-791.

7 Chapman PF, White GL, Jones MW, Cooper-Blacketer D, Marshall VJ, Irizarry $\mathrm{M}$ et al. Impaired synaptic plasticity and learning in aged amyloid precursor protein transgenic mice. Nat Neurosci 1999; 2: 271-276.

8 Shankar GM, Bloodgood BL, Townsend M, Walsh DM, Selkoe DJ, Sabatini BL. Natural oligomers of the Alzheimer amyloid-beta protein induce reversible synapse loss by modulating an NMDA-type glutamate receptor-dependent signaling pathway. J Neurosci 2007; 27: 2866-2875.

9 Snyder EM, Nong Y, Almeida CG, Paul S, Moran T, Choi EY et al. Regulation of NMDA receptor trafficking by amyloid-beta. Nat Neurosci 2005; 8: 1051-1058.

10 Lue LF, Kuo YM, Roher AE, Brachova L, Shen Y, Sue L et al. Soluble amyloid beta peptide concentration as a predictor of synaptic change in Alzheimer's disease. Am J Pathol 1999; 155: 853-862.

11 Represa A, Deloulme JC, Sensenbrenner M, Ben-Ari Y, Baudier J. Neurogranin: immunocytochemical localization of a brain-specific protein kinase C substrate. J Neurosci 1990; 10: 3782-3792.

12 Guadano-Ferraz A, Vinuela A, Oeding G, Bernal J, Rausell E. $\mathrm{RC}$ /neurogranin is expressed in pyramidal neurons of motor and somatosensory cortex in normal and denervated monkeys. J Comp Neurol 2005; 493: 554-570.

13 Xia Z, Storm DR. The role of calmodulin as a signal integrator for synaptic plasticity. Nat Rev Neurosci 2005; 6: 267-276.

14 Gerendasy DD, Sutcliffe JG.. RC3/neurogranin a postsynaptic calpacitin for setting the response threshold to calcium influxes. Mol Neurobiol 1997; 15: 131-163.

15 Pak JH, Huang FL, Li J, Balschun D, Reymann KG, Chiang C et al. Involvement of neurogranin in the modulation of calcium/calmodulindependent protein kinase II, synaptic plasticity, and spatial learning: a study with knockout mice. Proc Natl Acad Sci USA 2000; 97: $11232-11237$.

16 Huang KP, Huang FL, Jager T, Li J, Reymann KG, Balschun D. Neurogranin/RC3 enhances long-term potentiation and learning by promoting calcium-mediated signaling. J Neurosci 2004; 24: 10660-10669.

17 Bruel-Jungerman E, Davis S, Rampon C, Laroche S. Long-term potentiation enhances neurogenesis in the adult dentate gyrus. J Neurosci 2006; 26: 5888-5893.

18 Zhong L, Brown J, Kramer A, Kaleka K, Petersen A, Krueger JN et al. Increased prefrontal cortex neurogranin enhances plasticity and extinction learning. J Neurosci 2015; 35: 7503-7508.

19 Zhong L, Cherry T, Bies CE, Florence MA, Gerges NZ.. Neurogranin enhances synaptic strength through its interaction with calmodulin. $E M B O$ J 2009; 28: 3027-3039.

20 Fedorov NB, Pasinelli P, Oestreicher AB, DeGraan PN, Reymann KG. Antibodies to postsynaptic PKC substrate neurogranin prevent long-term potentiation in hippocampal CA1 neurons. Eur J Neurosci 1995; 7: 819-822.

21 Huang FL, Huang KP, Wu J, Boucheron C. Environmental enrichment enhances neurogranin expression and hippocampal learning and memory but fails to rescue the impairments of neurogranin null mutant mice. J Neurosci 2006; 26: 6230-6237.

22 Miyakawa T, Yared E, Pak JH, Huang FL, Huang KP, Crawley JN. Neurogranin null mutant mice display performance deficits on spatial learning tasks with anxiety related components. Hippocampus 2001; 11 : 763-775.

23 Zhabotinsky AM, Camp RN, Epstein IR, Lisman JE. Role of the neurogranin concentrated in spines in the induction of long-term potentiation. J Neurosci 2006; 26: 7337-7347.

24 Han KS, Cooke SF, Xu W. Experience-dependent equilibration of AMPARmediated synaptic transmission during the critical period. Cell Rep 2017; 18: 892-904.

25 Tarawneh R, D'Angelo G, Crimmins D, Herries E, Griest T, Fagan AM et al. Diagnostic and prognostic utility of the synaptic marker neurogranin in Alzheimer disease. JAMA Neurol 2016; 73(5): 561-571.

26 Fyfe I. Alzheimer disease: neurogranin in the CSF signals early Alzheimer disease and predicts disease progression. Nat Rev Neurol 2015; 11: 609 .

27 Portelius E, Zetterberg H, Skillback T, Tornqvist U, Andreasson U, Trojanowski JQ et al. Cerebrospinal fluid neurogranin: relation to cognition and neurodegeneration in Alzheimer's disease. Brain 2015; 138: 3373-3385.

28 Zetterberg H, Blennow K.. Neurogranin levels in cerebrospinal fluid: a new addition to the Alzheimer Disease Diagnostic Toolbox. JAMA Neurol 2015; 72: $1237-1238$.

29 Kester MI, Teunissen CE, Crimmins DL, Herries EM, Ladenson JH, Scheltens $\mathrm{P}$ et al. Neurogranin as a cerebrospinal fluid biomarker for synaptic loss in symptomatic Alzheimer disease. JAMA Neurol 2015; 72 : $1275-1280$.

30 Tarawneh R, D'Angelo G, Crimmins D, Herries E, Griest T, Fagan AM et al. Diagnostic and prognostic utility of the synaptic marker neurogranin in Alzheimer disease. JAMA Neurol 2016; 73: 561-571.

31 Wellington $\mathrm{H}$, Paterson RW, Portelius E, Tornqvist U, Magdalinou N, Fox NC et al. Increased CSF neurogranin concentration is specific to Alzheimer disease. Neurology 2016; 86: 829-835.

32 Chang JW, Schumacher E, Coulter PM 2nd, Vinters HV, Watson JB. Dendritic translocation of RC3/neurogranin mRNA in normal aging, Alzheimer disease and fronto-temporal dementia. J Neuropathol Exp Neurol 1997; 56: 1105-1118.

33 Reddy PH, Mani G, Park BS, Jacques J, Murdoch G, Whetsell W Jr et al. Differential loss of synaptic proteins in Alzheimer's disease: implications for synaptic dysfunction. J Alzheimers Dis 2005; 7 : 103-117 discussion 173-180.

34 George AJ, Gordon L, Beissbarth T, Koukoulas I, Holsinger RM, Perreau V et al. A serial analysis of gene expression profile of the Alzheimer's disease Tg2576 mouse model. Neurotox Res 2010; 17: 360-379.

35 Davidsson P, Blennow K. Neurochemical dissection of synaptic pathology in Alzheimer's disease. Int Psychogeriatr 1998; 10: 11-23.

36 Esteve C, Jones EA, Kell DB, Boutin H, McDonnell LA. Mass spectrometry imaging shows major derangements in neurogranin and in purine metabolism in the triple-knockout 3xTg Alzheimer mouse model. Biochim Biophys Acta 2017; 1865: 747-754.

37 Kaleka KS, Gerges NZ. Neurogranin restores amyloid beta-mediated synaptic transmission and long-term potentiation deficits. Exp Neurol 2016; 277: 115-123.

$38 \mathrm{Kim} \mathrm{J}$, Yoon JH, Kim YS. HIV-1 Tat interacts with and regulates the localization and processing of amyloid precursor protein. PLOS ONE 2013; 8: e77972.

39 Opazo P, Sainlos M, Choquet D. Regulation of AMPA receptor surface diffusion by PSD-95 slots. Curr Opin Neurobiol 2012; 22: 453-460.

40 Chater TE, Goda Y. The role of AMPA receptors in postsynaptic mechanisms of synaptic plasticity. Front Cell Neurosci 2014; 8: 401.

41 Bats C, Groc L, Choquet D. The interaction between Stargazin and PSD-95 regulates AMPA receptor surface trafficking. Neuron 2007; 53: 719-734.

42 Ehrlich I, Klein M, Rumpel S, Malinow R. PSD-95 is required for activitydriven synapse stabilization. Proc Natl Acad Sci USA 2007; 104: 4176-4181.

43 Kvartsberg H, Duits FH, Ingelsson M, Andreasen N, Ohrfelt A, Andersson K et al. Cerebrospinal fluid levels of the synaptic protein neurogranin correlates with cognitive decline in prodromal Alzheimer's disease. Alzheimers Dement 2015; 11: 1180-1190.

44 Thorsell A, Bjerke M, Gobom J, Brunhage E, Vanmechelen E, Andreasen N et al. Neurogranin in cerebrospinal fluid as a marker of synaptic degeneration in Alzheimer's disease. Brain Res 2010; 1362: 13-22.

45 Mattsson N, Insel PS, Palmqvist S, Portelius E, Zetterberg H, Weiner M et al. Cerebrospinal fluid tau, neurogranin, and neurofilament light in Alzheimer's disease. EMBO Mol Med 2016; 8: 1184-1196. 
46 Sun X, Dong C, Levin B, Crocco E, Loewenstein D, Zetterberg H et al. APOE epsilon4 carriers may undergo synaptic damage conferring risk of Alzheimer's disease. Alzheimers Dement 2016; 12: 1159-1166.

47 Alzheimer disease: elevated neurogranin levels reveal early synaptic damage in APOE* varepsilon4 carriers. Nat Rev Neurol 2016; 12: 430.

48 De Vos A, Struyfs H, Jacobs D, Fransen E, Klewansky T, De Roeck E et al. The cerebrospinal fluid neurogranin/BACE1 Ratio is a potential correlate of cognitive decline in Alzheimer's disease. J Alzheimers Dis 2016; 53 : 1523-1538.

49 Bereczki E, Francis PT, Howlett D, Pereira JB, Hoglund K, Bogstedt A et al. Synaptic proteins predict cognitive decline in Alzheimer's disease and Lewy body dementia. Alzheimers Dement 2016; 12: 1149-1158.

50 Dubois B, Feldman HH, Jacova C, Hampel H, Molinuevo JL, Blennow K et al. Advancing research diagnostic criteria for Alzheimer's disease: the IWG-2 criteria. Lancet Neurol 2014; 13: 614-629.

51 Oakley H, Cole SL, Logan S, Maus E, Shao P, Craft J et al. Intraneuronal beta-amyloid aggregates, neurodegeneration, and neuron loss in transgenic mice with five familial Alzheimer's disease mutations: potential factors in amyloid plaque formation. J Neurosci 2006; 26: 10129-10140.

52 Kimura R, Ohno M. Impairments in remote memory stabilization precede hippocampal synaptic and cognitive failures in 5XFAD Alzheimer mouse model. Neurobiol Dis 2009; 33: 229-235.

53 Moon M, Hong HS, Nam DW, Baik SH, Song H, Kook SY et al. Intracellular amyloid-beta accumulation in calcium-binding protein-deficient neurons leads to amyloid-beta plaque formation in animal model of Alzheimer's disease. J Alzheimers Dis 2012; 29: 615-628.

54 Decker H, Jurgensen S, Adrover MF, Brito-Moreira J, Bomfim TR, Klein WL et al. $\mathrm{N}$-methyl-D-aspartate receptors are required for synaptic targeting of Alzheimer's toxic amyloid-beta peptide oligomers. J Neurochem 2010; 115: 1520-1529.

55 Hsieh H, Boehm J, Sato C, Iwatsubo T, Tomita T, Sisodia S et al. AMPAR removal underlies Abeta-induced synaptic depression and dendritic spine loss. Neuron 2006; 52: 831-843.
56 Wang DM, Yang YJ, Zhang L, Zhang X, Guan FF, Zhang LF. Naringin enhances CaMKII activity and improves long-term memory in a mouse model of Alzheimer's disease. Int J Mol Sci 2013; 14: $5576-5586$

57 Zeng Y, Zhao D, Xie CW. Neurotrophins enhance CaMKII activity and rescue amyloid-beta-induced deficits in hippocampal synaptic plasticity. J Alzheimers Dis 2010; 21: 823-831.

58 Beique JC, Lin DT, Kang MG, Aizawa H, Takamiya K, Huganir RL. Synapsespecific regulation of AMPA receptor function by PSD-95. Proc Natl Acad Sci USA 2006; 103: 19535-19540.

59 Chun SK, Sun W, Park JJ, Jung MW. Enhanced proliferation of progenitor cells following long-term potentiation induction in the rat dentate gyrus. Neurobiol Learn Mem 2006; 86: 322-329.

60 Schmidt-Hieber C, Jonas P, Bischofberger J. Enhanced synaptic plasticity in newly generated granule cells of the adult hippocampus. Nature 2004; 429: 184-187.

61 Han NL, Wen J, Lin Q, Tan PL, Liou YC, Sheu FS. Proteomics analysis of the expression of neurogranin in murine neuroblastoma (Neuro-2a) cells reveals its involvement for cell differentiation. Int J Biol Sci 2007; 3: 263-273.

(c) (i) $(-)$ This work is licensed under a Creative Commons Attribution-NonCommercial-NoDerivs $\quad 4.0$

International License. The images or other third party material in this article are included in the article's Creative Commons license, unless indicated otherwise in the credit line; if the material is not included under the Creative Commons license, users will need to obtain permission from the license holder to reproduce the material. To view a copy of this license, visit http://creativecommons.org/licenses/by-nc-nd/4.0/

(C) The Author(s) 2018

Supplementary Information accompanies the paper on Experimental \& Molecular Medicine website (http://www.nature.com/emm) 